\title{
Prevalence and Prognostic Value of Myocardial Injury in the Initial Presentation of SARS-CoV-2 Infection among Older Adults
}

\section{Isabel Arnau-Barres}

Autonomous University of Barcelona

Ana Pascual-Dapena

Autonomous University of Barcelona

Inmaculada López-Montesinos

Institut Hospital del Mar d'Investigacions Mèdiques

Silvia Gómez-Zorrilla

Institut Hospital del Mar d'Investigacions Mèdiques

Luisa Sorli

Institut Hospital del Mar d'Investigacions Mèdiques

Marta Herrero

Institut Hospital del Mar d'Investigacions Mèdiques

Juan Pablo Horcajada

Institut Hospital del Mar d'Investigacions Mèdiques

Xavier Nogues

Institut Hospital del Mar d'Investigacions Mèdiques

Olga Vazquez

Institut Hospital del Mar d'Investigacions Mèdiques

Natalia García-Giralt

Institut Hospital del Mar d'Investigacions Mèdiques

Ramon Miralles

Autonomous University of Barcelona

Robert Güerri-Fernández ( $\nabla$ rguerri@psmar.cat )

Institut Hospital del Mar d'Investigacions Mèdiques

\section{Research Article}

Keywords: SARS-CoV-2 infection, myocardial injury (MIN), COVID-19, clinical implications

Posted Date: January 13th, 2021

DOI: https://doi.org/10.21203/rs.3.rs-134407/v1 
License: (c) (i) This work is licensed under a Creative Commons Attribution 4.0 International License. Read Full License 


\section{Abstract}

Myocardial involvement during SARS-CoV-2 infection has been reported in many prior publications. Data about this condition in older adults is scarce especially its role in clinical prognosis. We aim to study the prevalence and the clinical implications of acute myocardial injury (MIN) during SARS-CoV-2 infection, particularly in older patients.

\section{Methods}

Longitudinal observational study where all consecutive adult patients admitted to a COVID-19 unit between March to April 2020 were included. Those patients aged $\geq 65$ were considered as older patients. MIN was defined as at least 1 high-sensitive troponin (hs-TnT) concentration above the $99^{\text {th }}$ percentile upper reference limit with different sex-cutoff.

Results

Among the 634 patients admitted during the period of observation 365(58\%) had evidence of MIN (hs$\mathrm{TnT}>14 \mathrm{pg} / \mathrm{mL}$ ), and among those 224(61\%) were older adults. Individuals with acute MIN were more prone to be older, had more comorbidities, more functional decline at admission, and higher inflammatory parameters. Among older adults, MIN was associated with longer time to recovery compared to those without MIN [13 days(IQR 6-21) vs 9 days(IQR 5-17);p<0.001 repectively. In-hospital mortality was significantly higher in older adults with MIN at admission vs those without MIN [71(31\%) vs $11(12 \%) ; p<0.001]$. In a logistic regression model adjusting by age, sex, severity and Charlson comorbidity index the OR for in-hospital mortality was $2.1(95 \% \mathrm{Cl}: 1.02-4.42 ; \mathrm{p}=0.043)$ among those older adults with MIN at presentation.

\section{Conclusion}

MIN is frequent in individuals with SARS-CoV-2 infection, especially in older adults and in patients with pre-existing comorbidities and with higher inflammatory levels. Older adults with acute myocardial injury had greater time to clinical recovery, more severe presentation of the disease and higher odds of inhospital mortality.

\section{Introduction}

Myocardial involvement has been reported as one of the clinical presentations of individuals with severe acute respiratory syndrome coronavirus 2 (SARS-CoV-2) infection $(1,2)$. Cardiological symptoms associated with coronavirus diseased-19 (COVID-19) caused by SARS-CoV-2 may include a wide range of presentations from a troponin elevation reflecting an underlying non-ischemic myocardial injury to a myocardial infarction $(3,4)$. The diagnosis of myocardial injury (MIN) in hospitalized patients has significantly increased with the widespread use of high-sensitivity troponin (hs-TnT) assay. A precise definition of MIN is needed in order to distinguish it from a myocardial infarction. Whereas myocardial 
infarction is a form of MIN that requires clinical or electrical evidence of myocardial ischemia and necrosis, MIN is defined as at least 1 cardiac troponin concentration above the 99th percentile upper reference limit (5). Although this condition appears to be frequent during the current COVID-19 outbreak (6), the clinical relevance of MIN remains to be determined. It is keystone to understand whether acute MIN during the acute COVID-19 episode is a bystander epi-phenomenon or has a relevant clinical role in the outcome of the infection.

A consistent risk for myocardial injury MIN is age (3) and during the first COVID-19 wave the largest proportion of patients were over 65 years old (7). All of this makes this group of patients a target population to study the impact of myocardial injury MIN on SARS-CoV-2 infection.

Aging has a well-known detrimental impact on cardiac structure and vasculature. SARS-CoV-2 infection might cause a worsening of clinical conditions through different mechanisms, such as direct myocardial injury and endothelial binding, $T$ cell death, and increased inflammation (3). Considering that during the first wave the largest proportion of patients suffering of COVID-19 were over 65 years old (7), this group of patients results an interesting target population to study the impact of MIN on SARS-CoV-2 infection. However, no consistent data looking into this specific issue has been reported in older adults with SARSCoV-2 infection. Increasing evidence shows the association between COVID-19 and MIN along with increased mortality and overall a broader significance of this form of cardiac injury in COVID-19 outcomes (2). Despite being a prevalent and troublesome disease in this specific population, there are currently no large studies that deal with the manifestations of COVID-19 in this particular setting.

On the basis of our clinical observation in our cohort along with the available evidence, we hypothesized that SARS-CoV-2 might have early effect on the heart of older adults, presenting mainly as MIN since the very initial stages of infection. Accordingly, we aim to describe the prevalence and the clinical characteristics and prognosis of acute MIN as onset manifestation in a large cohort of older patients with confirmed SARS-CoV-2 infection.

\section{Methods}

This is a retrospective observational study conducted at Hospital del Mar in Barcelona, Spain. This hospital provides healthcare to an area up to 500,000 people. During the first wave of the pandemic the hospital was converted to a COVID-19 hospital with a COVID-19 unit that was equipped with 400 beds for in-hospital admission and with 80-beds for critical care. There is an electronic medical record and a centralized registry of all individuals admitted to the COVID-19 unit. For this study, we included all patients admitted to the COVID-19 unit for $\geq 48$ hours between March 9th and April 1st 2020.

Admission criteria to the unit was having a confirmed SARS-CoV-2 infection. This was by having a positive real-time polymerase chain reaction (rt-PCR) for SARS-CoV-2 in nasopharyngeal samples, obtained by trained personnel at hospital admission and fulfilling clinical diagnostic criteria (respiratory symptoms such as dyspnea, cough, sore throat, changes in taste/smell; or uni-/bilateral interstitial infiltrates in chest X-Ray). 
All subjects aged 65 and above with definite SARS-CoV-2 were included in the study. As admission protocol all patients admitted to the COVID-19 unit underwent a blood analysis with at least C-reactive protein, D-dimer, hs-TnT. Individuals with other conditions that could induce acute MIN and troponin rise were excluded: severe bacterial sepsis and other severe active infections, individuals with acute myocardial infarction (electrocardiographic changes suggesting acute ischemia and elevated myocardial ischemia markers), active known vasculitis, medications and substance intoxication. All eligible participants $\geq 65$ years were included and divided for comparison purposes between those with MIN and without it. We considered as a reference population the included younger adults ( $<65$ years old).

\section{Clinical variables, data source, and study outcomes}

Demographic, clinical and epidemiological data, as well as the information from the episode (laboratory workout, vital signs, treatment), were extracted from the electronic medical record using standardized data collection. Acute myocardial injury was defined by an hs-TnT value greater than the institutional upper limit of normal (14 pg/mL), without electrocardiographic changes that suggest acute ischemia (5). Clinical severity was assessed at admission with MEWS score $(8,9)$. Laboratory workups were systematized with an at-admission protocol that included a fasting blood draw with full blood count, electrolytes, renal and liver function, cardiac biomarkers (high-sensitivity troponin T (hs-TnT), N-terminalproB-type natriuretic peptide (NT-proBNP) and lactate dehydrogenase (LDH)), inflammatory markers (Creactive protein (CRP), interleukin-6 (IL-6), serum ferritin, and coagulation testing (D-dimer). Comorbidity was assessed using Charlson Comorbidity Index (10) and also categorized in no comorbidities, mild (1-2 comorbidities), severe ( $\geq 3$ comorbidities). A follow-up analysis was done to study the peak in troponin, and inflammatory markers.

Key outcomes included time to clinical stability (defined as the time the time elapsed since the patient's admission to: oxygen saturation >94\% (FiO2 21\%), normalized level of consciousness (baseline), $\mathrm{HR}<$ $100 \mathrm{rpm}$, systolic BP $>90 \mathrm{~mm} \mathrm{Hg}$, Temperature $<37.2^{\circ} \mathrm{C}$ ), admission to a critical care unit, or in-hospital mortality.

Acute myocardial injury was defined considering sex-specific cutoff for hs-TnT value greater than the institutional upper limit of normal, that is $9 \mathrm{ng} / \mathrm{l}$ for female and $16 \mathrm{ng} / \mathrm{l}$ for male, without electrocardiographic changes that suggest acute ischemia.

\section{Ethics considerations}

The Institutional Ethics Committee of Hospital del Mar of Barcelona approved the study and due to the nature of the retrospective data review, waived the need for informed consent from individual patients (CEIm 2020/9352).

\section{Statistical analysis}

Continuous variables are expressed as medians and interquartile range (IQRs). Categorical variables are expressed as frequencies (percentages). Continuous variables were compared using the Student t-test or 
the Mann-Whitney $U$ test, as appropriate, and categorical variables using $\chi 2$ test or the Fisher exact test, as appropriate.

Spearman correlation was used to test the association between inflammatory markers, and pro-NT-BNP and hs-TnT. A multivariate linear regression analysis was carried out to explore independent factors associated with hs-TnT levels. Those with $p<0.05$ in univariate analysis were introduced into the multivariate linear regression model.

To investigate the impact of factors on myocardial injury, logistic regression analyses were carried out to determine odd ratios (ORs) and 95\% confidence intervals (Cl) for covariates with myocardial injury (hs$\mathrm{TnT}>14$ ) as the bivariate outcome. We considered age and gender, daily habit, comorbidities (pre-existing coronary artery disease, hypertension, diabetes mellitus or cerebrovascular disease), lab tests, and

severity of the episode (MEWS score) and days with symptoms before admission for candidate variables in both regression models. An alternative model was fitted to study in-hospital mortality in individuals with acute myocardial injury. All statistical analyses were performed using STATA/MP V.14.0, and a twosided $p$ value of $<0.05$ was considered statistically significant.

\section{Results}

Among the 634 patients admitted during the period of observation 365 (58\%) had evidence of MIN (hs$\mathrm{TnT}>14 \mathrm{pg} / \mathrm{mL}$ ), and among those 224 (61\%) were older adults. The population and subgroups study are shown in figure 1.

\section{Older adults with and without acute myocardial injury}

Baseline characteristics of older adults with and without acute MIN were different (Table 1). Compared to those without MIN, older adults with cardiac injury were more likely to be older [mean age of 83 years (7588) vs 74 (68-78); $p<0.001$ ] and male sex ( $48 \%$ vs $33 \% ; p=0.02)$, with a higher prevalence of pre-existing cardiovascular disease (diabetes mellitus, hypertension, pre-existing heart disease) and with a clinical presentation more frequently with consciousness impairment and significantly less frequently with cough or fever, and no differences in prior to admission duration of symptoms (table1). Remarkably, older adults with MIN had significantly higher mortality rates than those without MIN [71 (31\%) vs 11 (12\%); $p<0.001]$. 
Table 1

Main clinical characteristics of the cohort. Differences between older adults with and without Myocardial Injury.

\begin{tabular}{|c|c|c|c|c|c|c|c|}
\hline \multirow{3}{*}{$\begin{array}{l}\text { Cohort Characteristics } \\
\text { Median age, years (IQR) }\end{array}$} & \multirow{2}{*}{\multicolumn{2}{|c|}{$\begin{array}{l}\text { Overall } \\
\mathrm{n}=313\end{array}$}} & \multicolumn{2}{|c|}{$\begin{array}{l}\text { Myocardial } \\
\text { Injury }\end{array}$} & \multicolumn{2}{|c|}{$\begin{array}{l}\text { Without } \\
\text { Myocardial } \\
\text { Injury }\end{array}$} & \multirow[t]{2}{*}{$\begin{array}{l}\mathrm{p}- \\
\text { value }\end{array}$} \\
\hline & & & $\mathrm{n}=22$ & & $\mathrm{n}=8$ & & \\
\hline & 79 & $\begin{array}{l}(73- \\
87)^{\star}\end{array}$ & 83 & $\begin{array}{l}(75- \\
88)\end{array}$ & 74 & $(68-78)$ & $<0.001$ \\
\hline Male sex (\%) & 134 & $(44 \%)$ & 105 & $(48 \%)$ & 29 & $(33 \%)$ & 0.022 \\
\hline $\begin{array}{l}\text { Totally Dependent for life } \\
\text { activities (\%) }\end{array}$ & 42 & $(14 \%)$ & 39 & $(18 \%)$ & 3 & $(3 \%)$ & 0.002 \\
\hline \multicolumn{8}{|l|}{ Comorbidities } \\
\hline Hypertension (\%) & 230 & $(74 \%)$ & 175 & $(78 \%)$ & 55 & $(62 \%)$ & 0.033 \\
\hline Diabetes Mellitus (\%) & 87 & $(28 \%)$ & 75 & $(33 \%)$ & 12 & $(13 \%)$ & $<0.001$ \\
\hline Chronic lung disease (\%) & 31 & $(10 \%)$ & 25 & $(11 \%)$ & 6 & $(7 \%)$ & 0.238 \\
\hline Chronic heart disease (\%) & 78 & $(25 \%)$ & 71 & $(32 \%)$ & 7 & $(8 \%)$ & $<0.001$ \\
\hline Chronic renal disease (\%) & 88 & $(28 \%)$ & 66 & $(29 \%)$ & 22 & $(24 \%)$ & 0.400 \\
\hline Chronic liver disease (\%) & 17 & $(\%)$ & 13 & $(6 \%)$ & 4 & $(4.5 \%)$ & 0.645 \\
\hline Dementia (\%) & 54 & $(17 \%)$ & 45 & $(20 \%)$ & 9 & $(3 \%)$ & 0.035 \\
\hline \multicolumn{8}{|l|}{ Charlson Comorbidy Index } \\
\hline No comorbitiy, n (\%) & 81 & $(25 \%)$ & 41 & $(21 \%)$ & 40 & $(45 \%)$ & $<0.001$ \\
\hline Medium-low (1-2), n (\%) & 104 & $(33 \%)$ & 76 & $(34 \%)$ & 28 & $(31 \%)$ & 0.416 \\
\hline High (33), n (\%) & 128 & $(42 \%)$ & 107 & $(45 \%)$ & 21 & $(24 \%)$ & $<0.001$ \\
\hline \multicolumn{8}{|l|}{ Onset symptoms } \\
\hline $\begin{array}{l}\text { Days with symptoms before } \\
\text { admission, median (IQR) }\end{array}$ & 6 & $(4-9)$ & 6 & $(3-9)$ & 7 & $(4-10)$ & 0.410 \\
\hline Dyspnoea (\%) & 158 & $(50 \%)$ & 119 & $(53 \%)$ & 39 & $(44 \%)$ & 0.137 \\
\hline Fever $(\%)$ & 222 & $(71 \%)$ & 146 & $(65 \%)$ & 76 & $(85 \%)$ & $<0.001$ \\
\hline Cough (\%) & 203 & $(65 \%)$ & 131 & $(58 \%)$ & 72 & $(81 \%)$ & $<0.001$ \\
\hline Anosmia (\%) & 16 & $(5 \%)$ & 7 & $(3 \%)$ & 9 & $(10 \%)$ & 0.011 \\
\hline Consciousness impairment (\%) & 58 & $(18 \%)$ & 52 & $(23 \%)$ & 6 & $(7 \%)$ & 0.001 \\
\hline
\end{tabular}




\begin{tabular}{|c|c|c|c|c|c|c|c|}
\hline $\begin{array}{l}\text { Confirmed Pulmonary Emboslism } \\
(\%)\end{array}$ & 15 & $(5 \%)$ & 9 & $(4 \%)$ & 6 & $(7 \%)$ & 0.309 \\
\hline $\begin{array}{l}\text { Acute Abnormalities in the EKG } \\
(\%)\end{array}$ & 13 & $(4 \%)$ & 12 & $(5 \%)$ & 1 & $(1 \%)$ & 0.090 \\
\hline \multicolumn{8}{|l|}{ Clinical markers at onset } \\
\hline $\begin{array}{l}\text { Median C-Reactive Protein mg/dl } \\
\text { (IQR) }\end{array}$ & 7.3 & $\begin{array}{l}(3.3- \\
15.4)\end{array}$ & 8.68 & $\begin{array}{l}(3.8- \\
18.6)\end{array}$ & 5.3 & $\begin{array}{l}(2.3- \\
11.2)\end{array}$ & 0.02 \\
\hline Procalcitonin mg/dl (IQR) & 0.152 & $\begin{array}{l}(0.09- \\
0.36)\end{array}$ & 0.21 & $\begin{array}{l}(0.10- \\
0.54)\end{array}$ & 0.10 & $\begin{array}{l}(0.07- \\
0.17)\end{array}$ & 0.02 \\
\hline $\begin{array}{l}\text { Median lymphocyte count /ml } \\
\text { (IQR) }\end{array}$ & 0.955 & $\begin{array}{l}(0.65- \\
1.4)\end{array}$ & 0.88 & $\begin{array}{l}(0.62- \\
1.29)\end{array}$ & 1.07 & $\begin{array}{l}(0.82- \\
1.63)\end{array}$ & 0.001 \\
\hline Median IL-6 pg/ml (IQR) & 49 & $\begin{array}{l}(19- \\
103)\end{array}$ & 45 & $\begin{array}{l}(12- \\
131)\end{array}$ & 57 & $(25-85)$ & 0.112 \\
\hline Median D-Dimer UI/I (IQR) & 1000 & $\begin{array}{l}(620- \\
2200)\end{array}$ & 1215 & $\begin{array}{l}(680- \\
2540)\end{array}$ & 780 & $\begin{array}{l}(450- \\
1330)\end{array}$ & $<0.001$ \\
\hline Median Pro-BNP ng/I (IQRS) & 487 & $\begin{array}{l}(222- \\
1391)\end{array}$ & 861 & $\begin{array}{l}(344- \\
3316)\end{array}$ & 235 & $\begin{array}{l}(101- \\
349)\end{array}$ & 0.001 \\
\hline Median Troponin ng/I (IQR) & 18 & $(14-37)$ & 6 & $(6-14)$ & 30 & $(20-54)$ & $<0.001$ \\
\hline Median Peak Troponin ng/I (IQR) & 19 & $(1-42)$ & 13 & $(5-14)$ & 35 & $(21-75)$ & $<0.001$ \\
\hline Median Creatinin mg/dl(IQR) & 0.99 & $\begin{array}{l}(0.77- \\
1.26)\end{array}$ & 1.08 & $\begin{array}{l}(0.85- \\
1.47)\end{array}$ & 0.79 & $\begin{array}{l}(0.67- \\
0.95)\end{array}$ & $<0.001$ \\
\hline Median PaFi (IQR) & 180 & $\begin{array}{l}(95- \\
289)\end{array}$ & 166 & $\begin{array}{l}(91- \\
281)\end{array}$ & 219 & $\begin{array}{l}(101- \\
310)\end{array}$ & 0.213 \\
\hline Median MEWS (IQR) & 2 & $(1-3)$ & 2 & $(2-3)$ & 2 & $(1-2)$ & 0.004 \\
\hline Median Cholesterol mg/ml (IQR) & 134 & $\begin{array}{l}(118- \\
161)\end{array}$ & 142 & $\begin{array}{l}(119- \\
162)\end{array}$ & 131 & $\begin{array}{l}(113- \\
143)\end{array}$ & 0.072 \\
\hline \multicolumn{8}{|l|}{ Treatment } \\
\hline Hydroxycholoroquine (\%) & 266 & $(89.5 \%)$ & 183 & $(86 \%)$ & 83 & $(95 \%)$ & 0.028 \\
\hline Azythromicin (\%) & 269 & $(90 \%)$ & 185 & $(87 \%)$ & 84 & $(96 \%)$ & 0.019 \\
\hline Tocilizumab (\%) & 35 & $(12 \%)$ & 18 & $(8.5 \%)$ & 17 & $(19 \%)$ & 0.008 \\
\hline Dexamethasone (\%) & 61 & $(19 \%)$ & 47 & $(21 \%)$ & 14 & $(15 \%)$ & 0.432 \\
\hline Methylprednisolone (\%) & 69 & $(22 \%)$ & 52 & $(23 \%)$ & 17 & $(19 \%)$ & 0.428 \\
\hline \multicolumn{8}{|l|}{ Clinical Outcomes } \\
\hline $\begin{array}{l}\text { Median Time to clinical recovery } \\
\text { days (IQR) }\end{array}$ & 12 & $(6-20)$ & 13 & $(6-21)$ & 9 & $(5-17)$ & 0.036 \\
\hline
\end{tabular}




\begin{tabular}{|llllllll} 
ICU admission (\%) & 46 & $(15 \%)$ & 29 & $(14 \%)$ & 17 & $(19 \%)$ & 0.230 \\
\hline Death (\%) & 82 & $(26 \%)$ & 71 & $(31 \%)$ & 11 & $(12 \%)$ & $<0.001$
\end{tabular}

\section{Comparison between Older and younger adults with acute myocardial injury}

As expected, older adults with MIN were different in many aspects compared with younger adults with MIN (Table 2). In brief, older adults with MIN were more likely to have cardiovascular risk factors (hypertension $78 \%$ vs $21 \% ; p<0.001)$, diabetes mellitus ( $33 \%$ vs $8 \% ; p<0.001)$, chronic heart disease $(30 \%$ vs $4.5 \%$; $p<0.001)$, among others. Interestingly, older adults with MIN presented more frequently with dyspnea as the main symptom ( $53 \%$ vs $34 \% ; \mathrm{p}<0.001)$. Moreover, when looking into the inflammatory response, CRP was significantly higher among older adults $(8.68 \mathrm{mg} / \mathrm{dl} v \mathrm{ss} 6.2 \mathrm{mg} / \mathrm{dl} ; \mathrm{p}=0.02)$ compared to younger patients, and also had significantly higher NT-ProBNP ( $861 \mathrm{UI} / \mathrm{I}$ vs $162 \mathrm{UI} / \mathrm{l} ; \mathrm{p}=0.007)$. Along with these differences, we found that older adults with MIN were more prone to die during hospitalization than younger adults with MIN (31\% vs $3 \% ; p<0.001)$ (table 2$)$. 
Table 2

Comparison between younger and older adults with Myocardial injury

\begin{tabular}{|c|c|c|c|c|c|}
\hline & \multicolumn{2}{|c|}{$\begin{array}{l}\text { Younger adults } \\
(n=321)\end{array}$} & \multicolumn{2}{|c|}{$\begin{array}{l}\text { Older } \\
\text { Adults ( } n=313)\end{array}$} & \multirow{2}{*}{$\begin{array}{l}\text { p- } \\
\text { value } \\
<0.001\end{array}$} \\
\hline Myocardial Injury & & $\begin{array}{l}N=141 \\
(43 \%)\end{array}$ & & $\begin{array}{l}N=224 \\
(71 \%)\end{array}$ & \\
\hline Median age, years (IQR) & 51 & $(42-58)$ & 83 & $(75-88)$ & $<0.001$ \\
\hline Male sex (\%) & 60 & $(43 \%)$ & 105 & $(47 \%)$ & 0.432 \\
\hline Totally Dependent for life activities (\%) & 3 & $(2 \%)$ & 39 & $(17 \%)$ & $<0.001$ \\
\hline \multicolumn{6}{|l|}{ Comorbidities } \\
\hline Hypertension (\%) & 30 & $(21 \%)$ & 175 & $(78 \%)$ & $<0.001$ \\
\hline Diabetes Mellitus (\%) & 12 & $(8 \%)$ & 75 & $(33 \%)$ & $<0.001$ \\
\hline Chronic lung disease (\%) & 6 & $(4 \%)$ & 25 & $(11 \%)$ & 0.021 \\
\hline Chronic heart disease (\%) & 7 & $(4.5 \%)$ & 71 & $(31 \%)$ & $<0.001$ \\
\hline Chronic renal disease (\%) & 99 & $(70 \%)$ & 66 & $(29 \%)$ & $<0.001$ \\
\hline Dementia (\%) & 2 & $(1.5 \%)$ & 45 & $(20 \%)$ & $<0.001$ \\
\hline \multicolumn{6}{|l|}{ Charlson Comorbidy Index, median (IQR) } \\
\hline No comorbitiy, n (\%) & 108 & $(74 \%)$ & 41 & $(18 \%)$ & $<0.001$ \\
\hline Medium-low (1-2), n (\%) & 18 & $(11 \%)$ & 79 & $(35 \%)$ & $<0.001$ \\
\hline High (33), n (\%) & 21 & $(15 \%)$ & 104 & $(47 \%)$ & $<0.001$ \\
\hline \multicolumn{6}{|l|}{ Onset symptoms } \\
\hline $\begin{array}{l}\text { Days with symptoms before admission, } \\
\text { median (IQR) }\end{array}$ & 16 & $(13-16)$ & 13.5 & $(12-15)$ & 0.627 \\
\hline Dyspnoea (\%) & 49 & $(34 \%)$ & 119 & $(53 \%)$ & $<0.001$ \\
\hline Fever (\%) & 87 & $(61 \%)$ & 146 & $(65 \%)$ & 0.532 \\
\hline Cough (\%) & 89 & $(63 \%)$ & 131 & $(58 \%)$ & 0.378 \\
\hline Diarrhoea (\%) & 29 & $(20 \%)$ & 48 & $(21 \%)$ & 0.844 \\
\hline Headache (\%) & 28 & $(20 \%)$ & 13 & $(6 \%)$ & $<0.001$ \\
\hline Anosmia (\%) & 43 & $(30 \%)$ & 7 & $(3 \%)$ & 0.011 \\
\hline Consciousness impairment (\%) & 5 & $(3 \%)$ & 52 & $(23 \%)$ & $<0.001$ \\
\hline Confirmed Pulmonary Emboslism (\%) & 4 & $(3 \%)$ & 9 & $(4 \%)$ & 0.553 \\
\hline
\end{tabular}




\begin{tabular}{|c|c|c|c|c|c|}
\hline Acute Abnormalities in the EKG (\%) & 2 & $(1.5 \%)$ & 12 & $(5 \%)$ & 0.090 \\
\hline \multicolumn{6}{|l|}{ Clinical markers at onset } \\
\hline Median C-Reactive Protein mg/dl (IQR) & 6.2 & $(3.8-18.6)$ & 8.68 & $(3.8-18.6)$ & 0.02 \\
\hline Procalcitonin mg/dl (IQR) & 0.22 & $(0.12-0.56)$ & 0.21 & $\begin{array}{l}(0.10- \\
0.54)\end{array}$ & 0.274 \\
\hline Median Pro-BNP ng/I (IQRS) & 162 & $(134-528)$ & 861 & $\begin{array}{l}(344- \\
3316)\end{array}$ & 0.007 \\
\hline Median Troponin ng/l (IQR) & 24 & $(18-41)$ & 30 & $(20-54)$ & $<0.001$ \\
\hline Median Peak Troponin ng/I (IQR) & 30 & $(20-94)$ & 37 & $(22-76)$ & $<0.001$ \\
\hline Median Creatinin mg/dl(IQR) & 0.91 & $(0.75-1.27)$ & 1.08 & $\begin{array}{l}(0.85- \\
1.47)\end{array}$ & 0.415 \\
\hline Median PaFi (IQR) & 188 & $(106-310)$ & 166 & $(91-281)$ & 0.299 \\
\hline Median MEWS (IQR) & 2 & $(1-3)$ & 2 & $(2-3)$ & 0.316 \\
\hline Median Cholesterol mg/ml (IQR) & 145 & $(108-168)$ & 142 & $(119-162)$ & 0.810 \\
\hline \multicolumn{6}{|l|}{ Treatment } \\
\hline Hydroxycholoroquine (\%) & 72 & $(53 \%)$ & 183 & $(86 \%)$ & $<0.001$ \\
\hline Azythromicin (\%) & 75 & $(55 \%)$ & 185 & $(87 \%)$ & 0.019 \\
\hline Tocilizumab (\%) & 16 & $(12 \%)$ & 18 & $(8.5 \%)$ & 0.318 \\
\hline Dexamethasone (\%) & 13 & $(9 \%)$ & 47 & $(21 \%)$ & 0.003 \\
\hline Methylprednisolone (\%) & 15 & $(12 \%)$ & 52 & $(23 \%)$ & 0.002 \\
\hline \multicolumn{6}{|l|}{ Clinical Outcomes } \\
\hline Median Time to clinical stability days (IQR) & 11 & $(6-26)$ & 13 & $(7-21)$ & 0.936 \\
\hline ICU admission (\%) & 23 & $(17 \%)$ & 29 & $(14 \%)$ & 0.397 \\
\hline Mechanical Ventilation & 21 & $(15 \%)$ & 45 & $(20 \%)$ & 0.223 \\
\hline Death (\%) & 4 & $(3 \%)$ & 71 & $(31 \%)$ & $<0.001$ \\
\hline
\end{tabular}

\section{Myocardial injury and inflammatory biomarkers in older adults}

In the older adults group, there was a significant correlation between hs-TnT at admission and IL- 6 levels (Spearman's Rho $0.201 ; p=0.028$ ) or CRPs (Spearman's Rho: $0.251 ; p=0.001$ ). A positive significant 
correlation between hs-TnT and NT-ProBNP was found (Spearman's Rho $=0.593 ; p<0.001$ ), showing some association between myocardial injury and myocardial dysfunction.

When comparing older adults with and without MIN, those with MIN had significantly higher non-specific inflammatory markers at admission compared to those without MIN such us CRP [median $8.68 \mathrm{mg} / \mathrm{dl}$ (IQR 3.8-18.6) vs $5.3 \mathrm{mg} / \mathrm{dl}$ (IQR 2.3-11.2); p=0.02], lower lymphocyte count [median count $0.88 / \mathrm{ml}(0.62-$ $1.29)$ vs $1.07 / \mathrm{ml}(0.82-1.63) ; p=0.001$ ] and higher levels of $D$-dimer [median $1215 \mathrm{UI} / \mathrm{I}(680-2540)$ vs 780 UI/I (450-1330); $p<0.001]$ (Table 1).

\section{Clinical outcomes in older adults with myocardial injury}

Median time to recovery among older adults was 12 days (IQR 6-20), however individuals with MIN showed longer time to clinical recovery compared to those without MIN [median 13 days (IQR 6-21) vs 9 days (IQR 5-17); $\mathrm{p}<0.001]$. In-hospital death was significantly higher in older adults with MIN at admission compared to those without MIN [71 (31\%) vs $11(12 \%) ; p<0.001]$.

In a logistic regression model adjusting by age, sex, severity and Charlson comorbidity index the OR for in-hospital mortality was $2.1(95 \% \mathrm{Cl} 1.02-4.42 ; \mathrm{p}=0.043)$ among those older adults with acute myocardial injury at presentation (Table 3).

Table 3

Logistic multivariable regression. Predictors of in-hospital mortality

\begin{tabular}{|llll|}
\hline & Odds-Ratio & $\mathbf{9 5 \%} \mathbf{C l}$ & p-value \\
\hline Myocardial Injury & 2.1 & $1.02-4.42$ & 0.043 \\
\hline Age & 1.08 & $1.05-1.11$ & $<0.001$ \\
Sex & 1.11 & $0.98-1.32$ & 0.093 \\
Charlson Index & 1.11 & $1.03-1.19$ & 0.004 \\
MEWS & 1.125 & $1.01-1.31$ & 0.019 \\
\hline
\end{tabular}

\section{Discussion}

We report worse prognosis among older adults presenting with MIN, even without myocardial necrosis, during the acute episode of SARS-CoV-2 infection. MIN led to a worse prognosis with more severe clinical presentation, prolonged time to recovery, and higher mortality rates among older adults, as had been reported in other series $(11,12)$. We found age, male gender and pre-existing cardiovascular disease to be key factors associated with higher prevalence of MIN. These are also well established risk factors for adverse events in general in outbreaks of respiratory virus infections (13)(14). Nonetheless, when controlling for these possible confounders, MIN was still associated with worse clinical prognosis. 
Recently, has been shown that high sensitivity troponin I improves mortality and cardiovascular risk stratification in older adults beyond traditional risk factors (15). In our study we found similar results in the SARS-CoV-2 infection with hs-TnT.

Based on the accepted definition of MIN and myocardial infarction (5), we considered as acute MIN cases where there was a significant increase in hs-TnT with an absence of electric signs of ischemia or myocarditis. Remarkably, we found this to be as frequent as $50 \%$ of our overall cohort, and up to $70 \%$ when looking into older adults. In other studies, acute MIN has been reported as less frequent, in up to $12 \%$ of patients with COVID-19 (16-18). The difference between our study and other prior reports may be explained because we are only considering cases that required hospitalization, which presumably means they have more severe forms of the disease, meanwhile prior studies included mixed series with inhospital and out-patients (16). Another additional reason is that the median age of our cohort was higher compared to previous studies (12).

It would be interesting to see if this myocardial injury also results significantly in myocardial dysfunction. What we have seen in our series is that individuals presenting with myocardial injury at admission had heart failure more frequently, both by clinical and biochemical signs measured by NT-proBNP. Unfortunately, we were not able to measure ejection fraction during the episode, due to unbelievable pressure on healthcare in the acute moment of the pandemic. All the same, with our data we are inclined to assess that there is an impairment of function as well.

Older adults showed significantly higher mortality than those younger counterparts, showing probably that the differences are not only because of MIN but with all the other comorbidities together added to age. However, there is evidence that show that patients with MIN are also more prone to die. There are many hypotheses trying to discern the causes of troponin elevation during SARS-CoV-2 infection, and also the role it plays in the evolution of the disease (6). An interesting hypothesis is that cardiac injury may reflect an ongoing pathological insult due to inflammation or secondary to hypoxemia (19). In our series, we found no differences between older adults with or without MIN in terms of the ratio of arterial oxygen partial pressure to fractional inspired oxygen (PaFi) at admission, moving us away from the theory that it is related to hypoxemia. On the other hand, we did find a positive correlation between all inflammatory markers that we studied and troponin levels, and have found consistently that individuals with MIN showed significantly higher inflammatory markers that those individuals without MIN. It also goes in consonance with the fact that older adults would be a more vulnerable population due to increased underlying inflammation secondary to the ageing of the immune system (3). Moreover, an increased immune response due to SARS-CoV-2 infection is one of the hallmarks of COVID-19. Acute myocardial events could be associated with inflammation triggered by SARS-CoV-2, as it has been suspected in other scenarios such as cytokine release syndrome, which seems to increase troponin after antigen receptor T-cell therapy and cytokine storm (6).

Ageing is associated with an immune alteration that has being characterized. Briefly it consists in the reduction in the number of peripheral blood naïve cells, with a relative increase in the frequency of 
memory cells. This leads to a dysregulation of immune control and an age increased inflammation called inflamm-aging, altogether are considered the hallmarks of immunosenescence (20). An older immune system is defined by these cells presenting a specific phenotype and responding abnormally to some external agents $(19,20)$. It has been reported that the acute infection of SARS-CoV-2 leads to an expansion of precisely immunosenescent cells (21). Altogether leads us to entertain the hypothesis that may be an additive effect between the SARS-CoV- 2 infection and age, where a more senescent immune system leads to increased tissue damage, including myocardium.

Our study has some limitations since it was conducted in a single center in the first wave of the COVID-19 outbreak. It has a mid-size sample and we were not able to conduct cardiac ultrasound or MRI, as a consequence, we were only able to define acute myocardial injury by troponin elevation without detailing myocardial tissue characteristics and haemodynamic function. Moreover, during this first wave many older adults with SARS-CoV-2 infection remained in long term care facilities. In that case we can say that our hospital was the reference center for many long term care facilities of the area and a fluid drainage of these long term care facilities even in the moments with highest incidence. Moreover, we find that a key strength of our study is how representative it is of an older adult population, belonging to a large city that has had high incidence of SARS-CoV-2 infection, which makes the results directly relevant to the clinical setting.

We can conclude that MIN was very common in individuals with SARS-CoV-2 infection, especially in older adults and in patients with pre-existing comorbidities and with higher inflammatory levels. We can also conclude that it impacted the clinical outcomes of individuals that experienced it, being associated with greater time to clinical recovery, more severe presentation of the disease and higher odds of in-hospital mortality. The consistent association that we found between inflammation and MIN makes the hypothesis of an inflammatory insult as responsible to heart damage plausible. This is more relevant in a group with higher inflammatory levels due to immune dysregulation linked to ageing and maybe deserves further attention. Ultimately, due to its widespread presence, and its likely role in prognosis, it is advisable that we direct attention to this matter.

\section{Declarations}

\section{Ethics approval and consent to participate}

The study was conducted according to the guidelines of the Declaration of Helsinki, and approved by the Institutional Review Board (The Institutional Ethics Committee of Hospital del Mar of Barcelona (CEIm2020/9352). Due to the nature of the retrospective data review, the IRB waived the need for informed consent from individual patients

\section{Consent for publication:}

All authors have reviewed the manuscript and the data and share consent for publication. 


\section{Availability of data and materials:}

We have not planned to upload our data for sharing. This data come from a general database that is being collected in real time information about all the admissions with SARS-CoV-2 infection in the hospital. However, datasets are available from the corresponding author on reasonable request

\section{Competing interests:}

The authors have declared that no conflict of interest exists.

\section{Funding:}

This work has received support and funding from Centro de Investigación Biomédica en Red de Fragilidad y Envejecimiento Saludable (CIBERFES) [Grant number CB16/10/00245], FEDER funds and the FIS Project from Instituto de Salud Carlos III, Ministerio de Ciencia e Innovación [Grant number (PI19/00019)]

\section{Authors' contributions:}

RGF,IAB, designed, conducted the study, prepared the manuscript, RGF, APD, ILM and SGZ did the analysis and supervised the results, NGG, LS, XN,MH,OV,RM APD,JH contributed to the manuscript. All the authors reviewed and approved the manuscript.

\section{Acknowledgments:}

The authors want to thank to the students of the Medicine School from Universitat Pompeu Fabra, Barcelona, Spain for their support and contribution to this work during these tough moments.

\section{References}

1. Lippi G, Lavie CJ, Sanchis-Gomar F. Cardiac troponin I in patients with coronavirus disease 2019 (COVID-19): Evidence from a meta-analysis. Prog Cardiovasc Dis. 2020;63(3):390-1. Available from: https://doi.org/10.1016/j.pcad.2020.03.001

2. Zou F, Qian Z, Wang Y, Zhao Y, Bai J. Cardiac Injury and COVID-19: A Systematic Review and MetaAnalysis. CJC Open. 2020; Available from: https://doi.org/10.1016/j.cjco.2020.06.010

3. Napoli C, Tritto I, Benincasa G, Mansueto G, Ambrosio G. Cardiovascular involvement during COVID19 and clinical implications in elderly patients. A review. Ann Med Surg. 2020;57(June):236-43. Available from: https://doi.org/10.1016/j.amsu.2020.07.054 
4. Cao J, Tu W-J, Cheng W, Yu L, Liu Y-K, Hu X, et al. Clinical Features and Short-term Outcomes of 102 Patients with Corona Virus Disease 2019 in Wuhan, China. Clin Infect Dis. 2020 Apr 2 [cited 2020 Jul 12]; Available from: http://www.ncbi.nlm.nih.gov/pubmed/32239127

5. Thygesen K, Alpert JS, Jaffe AS, Chaitman BR, Bax JJ, Morrow DA, et al. Fourth universal definition of myocardial infarction (2018). Eur Heart J. 2019;40(3):237-69.

6. Cheng R, Leedy D. COVID-19 and acute myocardial injury: The heart of the matter or an innocent bystander? Heart. 2020;106(15):1122-4.

7. Berenguer J, Ryan P, Rodríguez-Baño J, Jarrín I, Carratalà J, Pachón J, et al. Characteristics and predictors of death among 4035 consecutively hospitalized patients with COVID-19 in Spain. Clin Microbiol Infect. 2020; 26:1515-1535

8. Subbe CP, Davies RG, Williams E, Rutherford P, Gemmell L. Effect of introducing the Modified Early Warning score on clinical outcomes, cardio-pulmonary arrests and intensive care utilisation in acute medical admissions. Anaesthesia [Internet]. 2003 Aug [cited 2020 Aug 27];58(8):797-802. Available from: http://www.ncbi.nlm.nih.gov/pubmed/12859475

9. Subbe CP, Williams E, Fligelstone L, Gemmell L. Does earlier detection of critically ill patients on surgical wards lead to better outcomes? Ann R Coll Surg Engl [Internet]. 2005 Jul [cited 2020 Aug 27];87(4):226-32. Available from: http://www.ncbi.nlm.nih.gov/pubmed/16053678

10. Charlson ME, Pompei P, Ales KL, MacKenzie CR. A new method of classifying prognostic comorbidity in longitudinal studies: development and validation. J Chronic Dis [Internet]. 1987 [cited 2020 Nov 14];40(5):373-83. Available from: http://www.ncbi.nlm.nih.gov/pubmed/3558716

11. Yang HJ, Zhang YM, Yang M, Huang X. Predictors of mortality for patients with COVID-19 pneumonia caused by SARS-CoV-2. Eur Respir J. 2020;56(3).

12. Shi S, Qin M, Cai Y, Liu T, Shen B, Yang F, et al. Characteristics and clinical significance of myocardial injury in patients with severe coronavirus disease 2019. Eur Heart J. 2020;41(22):2070-9.

13. Zou L, Ruan F, Huang M, Liang L, Huang H, Hong Z, et al. SARS-CoV-2 Viral Load in Upper Respiratory Specimens of Infected Patients. N Engl J Med [Internet]. 2020 [cited 2020 Jul 12];382(12):1177-9. Available from: http://www.ncbi.nlm.nih.gov/pubmed/32074444

14. Lin L, Lu L, Cao W, Li T. Hypothesis for potential pathogenesis of SARS-CoV-2 infection-a review of immune changes in patients with viral pneumonia. Emerg Microbes Infect [Internet]. 2020 Mar 20;114. Available from: http://www.ncbi.nlm.nih.gov/pubmed/32196410

15. Tang O, Matsushita K, Coresh J, Hoogeveen RC, Windham BG, Ballantyne CM, et al. High-Sensitivity Cardiac Troponin I for Risk Strati fi cation in. J Am Geriatr Soc. 2020;1-9.

16. Kang Y, Chen T, Mui D, Ferrari V, Jagasia D, Scherrer-Crosbie M, et al. Cardiovascular manifestations and treatment considerations in COVID-19. Heart. 2020;106(15):1132-41.

17. Bavishi C, Bonow RO, Trivedi V, Abbott JD, Messerli FH, Bhatt DL. Acute myocardial injury in patients hospitalized with COVID-19 infection: A review. Progress in Cardiovascular Diseases. W.B. Saunders; 2020. 
18. Zhou B, She J, Wang Y, Ma X. The Clinical Characteristics of Myocardial injury 1 in Severe and Very Severe Patients with 2019 Novel Coronavirus Disease. J Infect [Internet]. 2020 Mar; Available from: https://linkinghub.elsevier.com/retrieve/pii/S0163445320301493

19. Imazio M, Klingel K, Kindermann I, Brucato A, De Rosa FG, Adler Y, et al. COVID-19 pandemic and troponin: Indirect myocardial injury, myocardial inflammation or myocarditis? Heart. 2020;106(15):1127-31.

20. Aiello A, Farzaneh F, Candore G, Caruso C, Davinelli S, Gambino CM, et al. Immunosenescence and its hallmarks: How to oppose aging strategically? A review of potential options for therapeutic intervention. Front Immunol. 2019;10(SEP):1-19.

21. De Biasi S, Meschiari M, Gibellini L, Bellinazzi C, Borella R, Fidanza L, et al. Marked T cell activation, senescence, exhaustion and skewing towards TH17 in patients with COVID-19 pneumonia. Nat Commun [Internet]. 2020 Jul 6;11(1):3434. Available from:

http://www.ncbi.nlm.nih.gov/pubmed/32632085

22. Ventura MT, Casciaro M, Gangemi S, Buquicchio R. Immunosenescence in aging: Between immune cells depletion and cytokines up-regulation. Clin Mol Allergy [Internet]. 2017;15:1-8. Available from: https://doi.org/10.1186/s12948-017-0077-0

\section{Figures}




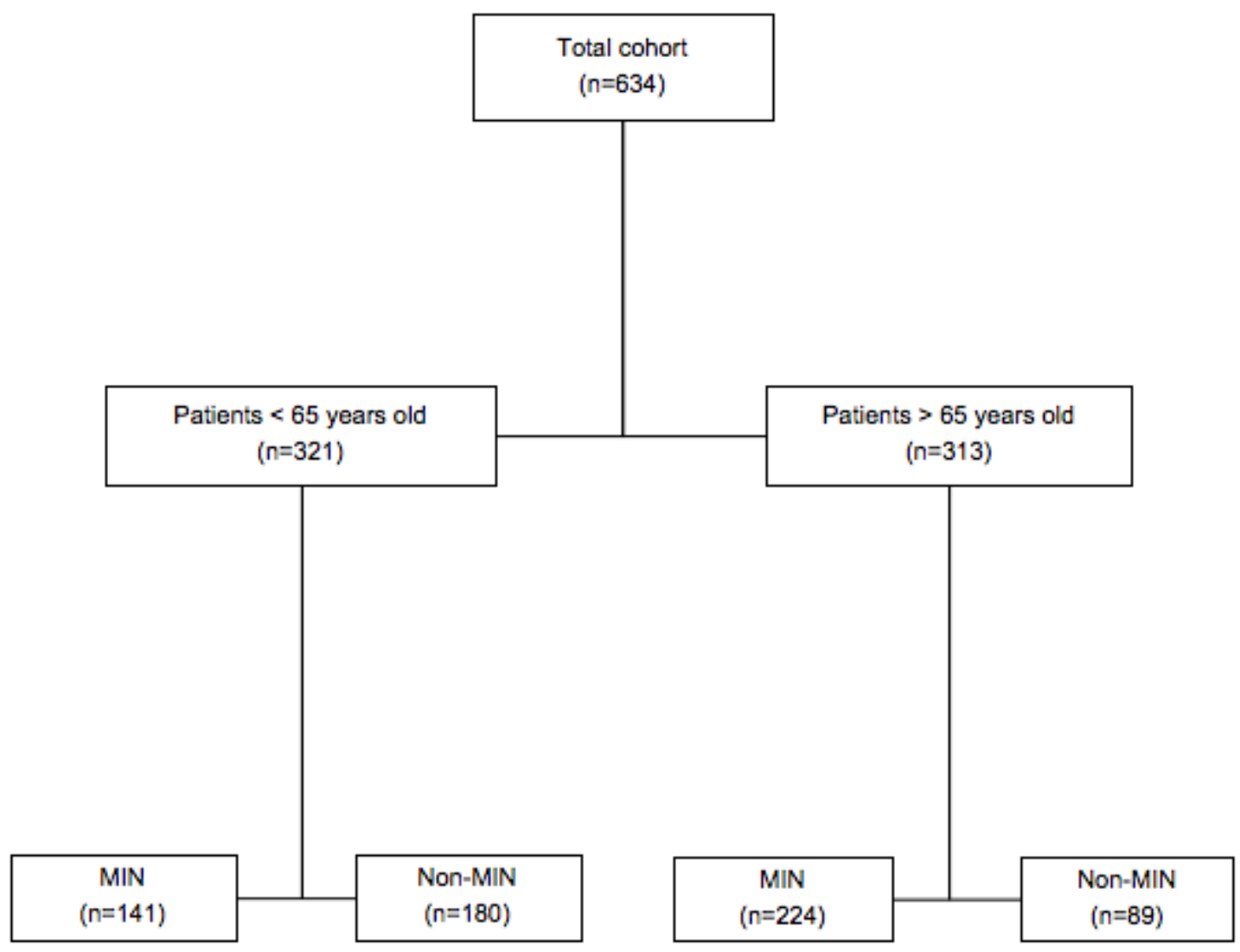

Abbreviations: MIN (myocardial injury).

Figure 1

Flowchart of the patients included in the study. 